\title{
Rapamycin Conditioning of Dendritic Cells Differentiated from Human ES Cells Promotes a Tolerogenic Phenotype
}

\author{
Kathryn M. Silk, ${ }^{1}$ Alison J. Leishman, ${ }^{1}$ Kevin P. Nishimoto, ${ }^{2}$ \\ Anita Reddy, ${ }^{2}$ and Paul J. Fairchild ${ }^{1}$ \\ ${ }^{1}$ Sir William Dunn School of Pathology, University of Oxford, South Parks Road, Oxford, OX1 3RE, UK \\ ${ }^{2}$ Translational Research and Immunology, Geron Corporation, 230 Constitution Drive, Menlo Park, CA 94025, USA
}

Correspondence should be addressed to Paul J. Fairchild, paul.fairchild@path.ox.ac.uk

Received 14 July 2011; Accepted 7 October 2011

Academic Editor: Ken-ichi Isobe

Copyright (C) 2012 Kathryn M. Silk et al. This is an open access article distributed under the Creative Commons Attribution License, which permits unrestricted use, distribution, and reproduction in any medium, provided the original work is properly cited.

\begin{abstract}
While human embryonic stem cells (hESCs) may one day facilitate the treatment of degenerative diseases requiring cell replacement therapy, the success of regenerative medicine is predicated on overcoming the rejection of replacement tissues. Given the role played by dendritic cells (DCs) in the establishment of immunological tolerance, we have proposed that DC, rendered tolerogenic during their differentiation from hESC, might predispose recipients to accept replacement tissues. As a first step towards this goal, we demonstrate that DC differentiated from H1 hESCs (H1-DCs) are particularly responsive to the immunosuppressive agent rapamycin compared to monocyte-derived DC (moDC). While rapamycin had only modest impact on the phenotype and function of moDC, H1-DC failed to upregulate CD40 upon maturation and displayed reduced immunostimulatory capacity. Furthermore, coculture of naïve allogeneic T cells with rapamycin-treated H1-DC promoted an increased appearance of CD25 $5^{\text {hi }}$ Foxp $3^{+}$regulatory T cells, compared to moDC. Our findings suggest that conditioning of hESC-derived DC with rapamycin favours a tolerogenic phenotype.
\end{abstract}

\section{Introduction}

Human embryonic stem cells (hESCs) derived under conditions compliant with their downstream clinical application, serve as a renewable source of cell types that may one day enable the replacement of tissues whose function has become compromised by chronic or degenerative disease [1]. Nevertheless, the routine implementation of cell replacement therapy (CRT) requires strategies to address the immunological barriers encountered by the use of hESC of allogeneic origin [2]. While conventional immunosuppression offers a potential solution to the immunogenicity of hESC-derived tissues, the risks inherent in its protracted use make the induction of transplantation tolerance an attractive alternative.

Dendritic cells (DCs) play a critical role in determining the outcome of antigen presentation to naive $\mathrm{T}$ cells, either promoting their activation and subsequent immunity, or favouring the induction of tolerance [3]. The delivery of foreign antigen to DC in the steady state by conjugation to monoclonal antibodies ( $\mathrm{mAbs}$ ) specific for the surface receptor CD205, was, for instance, found to render recipient mice specifically tolerant to the antigen upon subsequent immunization [4]. Such findings have been extended to a transplantation setting by demonstrating how administration of immature donor DC to mice across a minor histocompatibility barrier is sufficient to secure the indefinite survival of donor skin grafts. In this model, the resulting tolerance could be attributed to the polarisation of responding $\mathrm{T}$ cells towards a regulatory phenotype, characterised by upregulation of the transcription factor Foxp3 [5]. Such findings, together with early success at inducing tolerance in healthy human volunteers by the administration of immature antigen-pulsed monocyte-derived DC (moDC) [6], augur well for the future use of DC as a conditioning regime in the context of CRT. Indeed, the recent description of protocols for the differentiation of DC from hESC under conditions substantially free of animal products paves the way for such an approach: given that this source of DC would share with 
the replacement tissue the very alloantigens to which tolerance must be established, their administration in advance of CRT might be anticipated to condition the recipient to accept the transplanted tissue, providing the DC have first been rendered stably tolerogenic [7]. Accordingly, Senju et al. generated DC expressing the inhibitory receptor programmed death ligand 1 (PD-L1) by genetic modification of the parent hESC line [8], a similar approach in the mouse having successfully yielded DC capable of preventing the onset of experimental autoimmune encephalomyelitis by induction of tolerance to myelin antigens [9]. While such a strategy is clearly promising, the administration of genetically modified cells to patients poses additional regulatory barriers, suggesting that exposure of DC to pharmacological agents, known to promote a tolerogenic phenotype, may prove to be a more pragmatic approach [10].

The macrocyclic triene antibiotic, rapamycin, displays potent immunosuppressive properties that are routinely employed to facilitate whole-organ transplantation. In addition to its systemic use, however, rapamycin has been shown to render DC profoundly protolerogenic through inhibition of mammalian target of rapamycin (mTOR) signalling pathways. In the mouse, rapamycin-treated DC display profoundly suppressed allostimulatory capacity in vitro and enhanced propensity for the induction of Foxp $3^{+}$regulatory $\mathrm{T}$ (Treg) cells [11]. Furthermore, exposure to rapamycin, unlike other immunosuppressive agents, leads to the upregulation of CCR7 by both mouse and human DC and a commensurate increase in responsiveness to CCL19, compatible with their trafficking in vivo to regional lymph nodes [12, 13]. Furthermore, the administration of rapamycin-treated recipient DC pulsed with donor alloantigens has secured the indefinite survival of tissue allografts in various animal models [14-16], the resulting tolerance having been demonstrated to rely on the expansion of antigen-specific Treg cells [17]. Nevertheless, despite its compelling credentials, rapamycin has been reported to exert quite distinct effects on human DC, depending on the source and subset involved [18]. We have, therefore, investigated the compatibility of protocols for the differentiation of DC from the H1 hESC line (H1-DC) with the use of rapamycin. Here we report that H1-DCs are peculiarly sensitive to the immunomodulatory effects of rapamycin, compared with conventional moDC, as evidenced by the specific loss of immunogenicity and enhanced capacity to polarise responding $\mathrm{T}$ cells towards a regulatory phenotype. Our findings provide an important first step towards the use of DC differentiated from hESC in the establishment of tolerance to replacement tissues, providing a proof of concept for their future application in regenerative medicine.

\section{Materials and Methods}

2.1. Isolation of Primary Cells. Monocytes and naïve $\mathrm{T}$ cells were isolated from peripheral blood mononuclear cells (PBMCs) of buffy coats (NHS Blood Transfusion Service) or from blood provided by volunteers under informed consent using CD14-coated beads or naïve $\mathrm{CD}^{+} \mathrm{T}$ cell selection kit (Miltenyi Biotec). Cell populations were positively selected or depleted from PBMC using AutoMACS separation according to the manufacturer's instructions.

2.2. Culture of hESC. H1 ESCs were cultured in X-VIVO-10 medium (without gentamycin or phenol red, Lonza) supplemented with nonessential amino acids (PAA Laboratories $\mathrm{GmbH}$ ), $2 \mathrm{mM}$ L-glutamine (PAA Laboratories $\mathrm{GmbH}$ ), $50 \mu \mathrm{M}$ 2-mercaptoethanol (Sigma), $0.5 \mathrm{ng} / \mathrm{mL}$ recombinant human transforming growth factor $\beta$ (TGF- $\beta$, R\&D Systems), and $80 \mathrm{ng} / \mathrm{mL}$ recombinant human basic fibroblast growth factor (bFGF, R\&D Systems) on 6-well plates, previously coated with Matrigel (phenol red-free, growth factor reduced, BD Biosciences) diluted 1:30 using icecold knockout Dulbecco's Modified Eagle's Medium (KODMEM, Invitrogen). Supplemented X-VIVO-10 medium was replaced daily except the day following passaging.

Human ESCs were routinely passaged as cell clusters of about $0.5 \mathrm{~mm}$ diameter every 4-6 days. For passaging, colonies were incubated in filter-sterilised warm collagenase IV (Invitrogen) until detachment of the stromal cells. Stromal cells were removed by washing with Dulbecco's PhosphateBuffered Saline (DPBS) and hESC were scraped off into supplemented X-VIVO-10 Medium for 1:5 passaging. All cell cultures were incubated in a humidified incubator at $37^{\circ} \mathrm{C}$ and $5 \% \mathrm{CO}_{2}$.

2.3. Differentiation of hESC. H1 hESCs were plated at $3 \times 10^{6}$ per well of 6-well ultralow attachment (ULA) plates (Costar) in a total volume of $4 \mathrm{~mL}$ of X-VIVO-15 medium (Lonza), supplemented with $1 \mathrm{mM}$ sodium pyruvate, nonessential amino acids, $2 \mathrm{mM}$ L-glutamine (all PAA Laboratories $\mathrm{GmbH}$ ) and $5 \mu \mathrm{M} 2$-mercaptoethanol (Sigma). The following growth factors were added: $50 \mathrm{ng} / \mathrm{mL}$ recombinant human bone morphogenetic protein-4 (BMP-4, R\&D Systems), $50 \mathrm{ng} / \mathrm{mL}$ recombinant human vascular endothelial growth factor (VEGF, R\&D Systems), $20 \mathrm{ng} / \mathrm{mL}$ recombinant human stem cell factor (SCF, R\&D Systems), and $50 \mathrm{ng} / \mathrm{mL}$ recombinant human granulocyte macrophage-colony stimulating factor (GM-CSF, R\&D Systems). After 2-3 days, the medium was topped up with $2 \mathrm{~mL}$ of fresh supplemented X-VIVO15 medium to produce a total volume of $6 \mathrm{~mL}$. Subsequent feeding was performed every 2-3 days by replacing $2-3 \mathrm{~mL}$ of old medium with new supplemented X-VIVO-15 medium from which every 5 days a growth factor was removed starting with BMP-4 at day 5, followed by VEGF at day 10 and SCF at day 15 of differentiation [19]. Once macrophage-like cells were observed, $25 \mathrm{ng} / \mathrm{mL}$ of IL-4 (Peprotech) was added, which was increased stepwise to $100 \mathrm{ng} / \mathrm{mL}$.

On days 30-35, monocytes were harvested by gentle pipetting, leaving adherent macrophages in the culture dish. The cell suspension was passed through a $70 \mu \mathrm{m}$ cell strainer (BD Falcon) to remove cellular debris, washed with DPBS and plated at $1-1.5 \times 10^{6}$ monocytes per well of a 6 -well Cellbind plate (Corning) in X-VIVO-15 supplemented with $50 \mathrm{ng} / \mathrm{mL}$ GM-CSF and $100 \mathrm{ng} / \mathrm{mL}$ IL-4.

2.4. Derivation of DC from Human Monocytes. Monocytes were cultured in RPMI 1640 (Invitrogen) supplemented with 
$2 \mathrm{mM}$ L-glutamine (PAA laboratories $\mathrm{GmbH}$ ), $50 \mathrm{U} / \mathrm{mL}$ penicillin (PAA laboratories $\mathrm{GmbH}$ ), $50 \mu \mathrm{g} / \mathrm{mL}$ streptomycin (PAA laboratories $\mathrm{GmbH}$ ), 10\% heat-inactivated and filtersterilised fetal bovine serum (FBS), $50 \mathrm{ng} / \mathrm{mL}$ GM-CSF, and $100 \mathrm{ng} / \mathrm{mL}$ IL-4 on 6-well Cellbind plates for 6-8 days.

2.5. DC Maturation and Rapamycin Treatment. Two days after monocytes were plated, monocyte-derived and hESCderived immature DC were treated with $10 \mathrm{ng} / \mathrm{mL}$ and 5$7 \mathrm{ng} / \mathrm{mL}$ of rapamycin (Sigma), respectively. On day 5, DCs were matured for $48 \mathrm{hr}$ using a maturation cocktail consisting of $50 \mathrm{ng} / \mathrm{mL}$ of GM-CSF (R\&D Systems), $100 \mathrm{ng} / \mathrm{mL}$ IL-4 (R\&D Systems), $20 \mathrm{ng} / \mathrm{mL}$ IFN $\gamma$ (R\&D Systems), $50 \mathrm{ng} / \mathrm{mL}$ TNF $\alpha$ (R\&D Systems), $10 \mathrm{ng} / \mathrm{mL}$ of IL-1 $\beta$ (R\&D Systems), and $1 \mu \mathrm{g} / \mathrm{mL} \mathrm{PGE}_{2}$ (Sigma). On day 6-7, DCs were harvested by gentle pipetting, passed through a $70 \mu \mathrm{m}$ cell strainer, centrifuged, and resuspended prior to their use in experiments.

2.6. Allogeneic Mixed Leukocyte Reaction (MLR). DCs were incubated in $10 \mu \mathrm{g} / \mathrm{mL}$ mitomycin C (Sigma) in supplemented RPMI 1640 at $37^{\circ} \mathrm{C}$ for 30 minutes. Cells were washed, resuspended in supplemented RPMI 1640, and plated in triplicate to give either $2.5 \times 10^{3}$ cells, $5 \times 10^{3}$ cells, or $1 \times 10^{4}$ cells in a total volume of $100 \mu \mathrm{l}$ per well using 96 -well roundbottom plates (Corning). Naïve $\mathrm{CD} 4^{+} \mathrm{T}$ cells were plated at $5 \times 10^{4}$ cells per well to yield a stimulator to responder ratio of $1: 5,1: 10$, and $1: 20$ and a total volume of $200 \mu \mathrm{l} /$ well. Wells containing $\mathrm{T}$ cells and mitomycin C-treated DC alone were included as controls for background proliferation of either cell type. Cells were incubated for 5 days at $37^{\circ} \mathrm{C}$, after which $\mathrm{T}$ cells were pulsed with $0.5 \mu \mathrm{Ci}$ of $\left[{ }^{3} \mathrm{H}\right]$-thymidine per well for $18 \mathrm{hr}$ before harvesting.

2.7. DC-T-Cell Cocultures. DC $\left(2 \times 10^{5}\right)$ and $1 \times 10^{6} \mathrm{~T}$ cells were cocultured in supplemented RPMI 1640 using 24-well Cellbind plates (Corning). After 7 days of coculture, cells were harvested and stained for CD4, CD25, and Foxp3 and analysed by flow cytometry as described below.

2.8. Flow Cytometry. Cells were incubated for $15 \mathrm{~min}$ in blocking solution ( $5 \%$ normal rat serum, $0.5 \%$ bovine serum albumin, and $0.1 \% \mathrm{NaN}_{3}$ in DPBS) on ice. Cells were washed with DPBS containing $1 \%$ FBS and $0.1 \% \mathrm{NaN}_{3}$ and resuspended in this solution together with one or several of the following fluorescently labelled antibodies: SSEA-4 (clone: MC-813-70, R\&D Systems), eZFluor anti-human CD4-FITC and either CD25-APC or CD25-AF488 Cocktail (eBioscience), CD83 (HB15e, AbD Serotec), CD86 (BU63, AbD Serotec), CD40 (LOB7/6, AbD Serotec), PD-L1 (AbD Serotec), CD127 (40131, R\&D Systems), CTLA-4 (BNI3, BD Pharmingen), MHC II HLA-DR/DQ/DP (WR18, AbD Serotec), CD80 (MEM-233, AbD Serotec), CD45 (15.2, AbD Serotec), CD14 (MEM18, AbD Serotec), CD11c (BU15, AbD Serotec), and CD13 (AbD Serotec). Cells were incubated at $4^{\circ} \mathrm{C}$ in the dark for 30-60 minutes. For the last 10 minutes, $250 \mathrm{ng} / \mathrm{mL} 7-\mathrm{AAD}$ was added. Cells were washed, fixed in $2 \%$ formaldehyde, and analysed by flow cytometry.
Intracellular staining was performed according to the manufacturer's instructions using permeabilisation and fixation buffers (eBioscience) and antibodies specific for Oct-4 (240408, R\&DSystems) or Foxp3 (eBioscience).

\section{Results}

3.1. Differentiation and Characterisation of DC from the H1 hESC Line. In order to investigate whether protocols we have established previously for the differentiation of DC from hESC might be compatible with the use of rapamycin, we made use of the well-characterised H1 hESC line. In keeping with its downstream clinical application, $\mathrm{H} 1$ was maintained in serum-free medium devoid of animal products and feeder cells, as described previously $[20,21]$. Under these conditions, $\mathrm{H} 1$ formed compact colonies with clearly defined boarders (Figure 1(a)), the individual cells displaying a high nucleus: cytoplasm ratio and prominent heterochromatin. Flow cytometric analysis revealed expression of the transcription factor Oct- 4 and stage-specific embryonic antigen 4 (SSEA-4), both of which are known to strongly correlate with pluripotency (Figure 1(b)).

The differentiation of $\mathrm{H} 1$ was directed along the DC lineage in ultralow attachment plates by exposure to a cocktail of growth factors consisting of BMP-4, VEGF, SCF, and GMCSF, as described previously [19]. The initiation of hematopoiesis was apparent by day 20 of culture, as evidenced by the appearance of $\mathrm{CD} 45^{+}$cells, although the lack of expression of $\mathrm{CD} 13$, CD14, and CD11c suggested that commitment to the myeloid lineage had yet to occur (Figure 2(a)). In contrast, by day 27 of culture, a small proportion of cells, residing within a population expressing intermediate levels of CD45, had upregulated these markers, consistent with their progressive commitment to the myeloid lineage (Figure 2(b)). Indeed, from day 28 of culture onwards, cells with the characteristic morphology of human DC could be identified within cultures, either as clusters with prominent veils of cytoplasm or individual cells with long dendrites (Figure 2(c)).

By day 33 of culture, up to $21 \%$ of cells had adopted a CD $45^{\text {hi }}$ phenotype, the majority of which were CD11c ${ }^{+}$ (Figure 2(d)). Whereas these cells predominantly expressed MHC class I and CD86, CD83, and MHC class II expression were low, consistent with the phenotype of immature DC. Culture of H1-DC for 2 days in a cocktail of cytokines consisting of GM-CSF, IL- 4, IFN $\gamma$, TNF $\alpha$, IL-1 $\beta$, and PGE $_{2}$ induced their maturation, as evidenced by the upregulation of CD83, similar to moDC (Figure 2(e)). Although, as previously described, MHC class II was not upregulated by H1DC to the same extent as their monocyte-derived counterparts [19], surface expression of the costimulatory molecules CD40, CD80, and CD86 was consistent with our previous reports of the ability of this novel source of DC to stimulate proliferative responses among naïve allogeneic T cells [19].

3.2. Rapamycin Reduces the Immunogenicity of H1-DC. We next investigated whether the exposure of H1-DC to rapamycin could promote the acquisition of a protolerogenic phenotype, similar to that described for other populations 


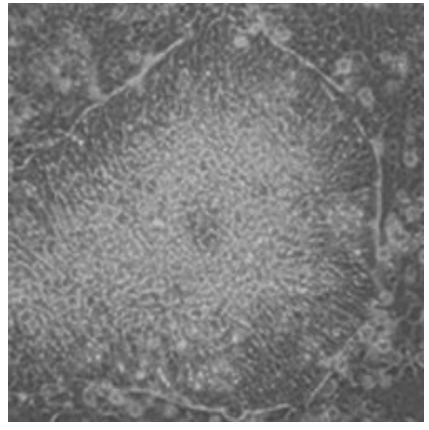

(a)
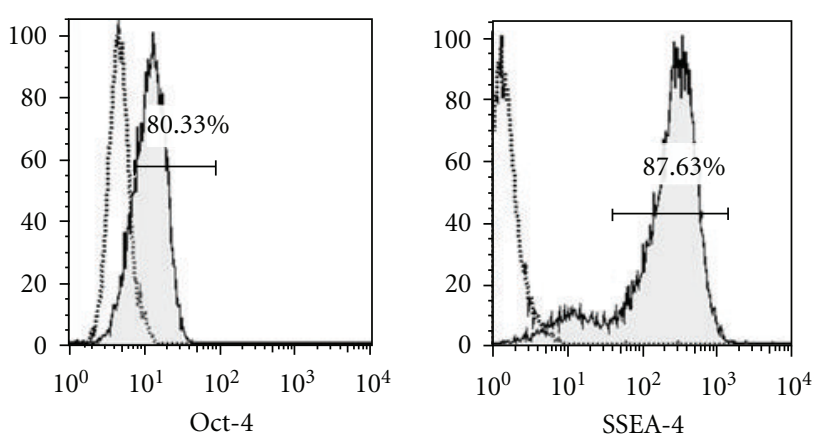

(b)

FIgURE 1: Maintenance of the H1 hESC line. (a) Colony of H1 hESC showing the morphology typical of pluripotent stem cells, including prominent boarders ( $\times 20$ magnification). (b) Expression by H1 hESC of the transcription factor Oct-4 and the surface marker SSEA-4, both of which correlate with pluripotency. Dead cells were removed from flow cytometric analysis using 7-AAD staining. Open histograms represent appropriate isotype controls.

of mouse and human DC [11-13]. Accordingly, we cultured H1-DC with rapamycin for 3 days prior to inducing their maturation with proinflammatory cytokines and assessed their surface phenotype and immunostimulatory capacity in the allogeneic MLR. Whereas the addition of $10 \mathrm{ng} / \mathrm{mL}$ of rapamycin to moDC had only a modest impact on their viability, H1-DC proved especially sensitive to its toxicity, undergoing significant levels of apoptosis at concentrations greater than $7 \mathrm{ng} / \mathrm{mL}$, as described in other studies [22]. Nevertheless, careful titration of the compound revealed that exposure of H1-DC to concentrations between 5 and $7 \mathrm{ng} / \mathrm{mL}$ exerted immunomodulatory effects without compromising their viability. Interestingly, conditioning of H1-DC with rapamycin did not appear to inhibit their maturation since they upregulated CD83 and CD86 and maintained surface expression of MHC class II and the inhibitory receptor PDL1 (Figure 3(a)), strongly implicated in the polarisation of naïve T cells towards a Treg phenotype [23]. Significantly, however, H1-DC consistently failed to up-regulate CD40 following exposure to rapamycin, even though higher concentrations of the pharmacological agent had little impact on CD40 expression by moDC (Figure 3(b)). Consistent with their reduced levels of CD40 expression, the immunostimulatory capacity of rapamycin-treated H1-DC was significantly reduced in cocultures with naïve allogeneic $\mathrm{T}$ cells (Figure $3(\mathrm{c})$ ). In contrast, $10 \mathrm{ng} / \mathrm{mL}$ of rapamycin exerted only modest inhibitory effects on the capacity of moDC to stimulate proliferative responses among naïve allogeneic $\mathrm{T}$ cells (Figure $3(\mathrm{c})$ ).

\subsection{Rapamycin-Treated H1-DC Polarise Nä̈ve T Cells towards} a Regulatory Phenotype. Given the reduced immunostimulatory capacity of rapamycin-treated H1-DC and their acquisition of a $\mathrm{CD} 40^{\text {lo }} \mathrm{PD}-\mathrm{L}^{+}$phenotype, we next investigated whether their coculture with naïve $\mathrm{CD} 4^{+} \mathrm{T}$ cells might favour the induction of Treg cells, defined as $\mathrm{CD} 4^{+} \mathrm{CD} 25^{\text {hi }}$ cells with persistent expression of Foxp3. Although at the outset, $\mathrm{T}$ cells enriched for $\mathrm{CD}^{+}$cells were predominantly Foxp3 $3^{-}$ (Figure 4(a)), coculture with immature H1-DC for 7 days, resulted in up to $8.5 \%$ of $\mathrm{CD} 4{ }^{+} \mathrm{CD} 25^{\text {hi }}$ cells retaining Foxp3 expression by the end of the culture period (Figure 4(b)). When the H1-DC had been matured prior to coculture with naïve allogeneic $\mathrm{T}$ cells, the proportion of cells committed to the Treg cell lineage increased marginally to $12.5 \%$. However, the use of H1-DC, which had been induced to mature following exposure to rapamycin, consistently resulted in a significant increase in the induction of Treg cells which represented approximately $26.5 \%$ of $\mathrm{CD} 4^{+} \mathrm{CD} 25^{\mathrm{hi}}$ cells, similar results being obtained in four independent experiments. By contrast, rapamycin conditioning of moDC exerted only a marginal effect on the ability of the cells to polarise responding T cells towards a regulatory phenotype (Figure 4(b)).

Given that the identification of bona fide human Treg cells is confounded by the universal upregulation of CD25 by activated T cells and their transient expression of Foxp3, irrespective of final lineage commitment, we investigated whether CD25 ${ }^{\text {hi }}$ Foxp $3^{+}$cells appearing in such cultures displayed other known phenotypic features of Treg cells. Cells coexpressing CD25 and Foxp3 were found to express CTLA4 (Figure 5(a)), while lacking expression of the $\alpha$ subunit of the IL-7R, CD127 (Figure 5(b)), such a phenotype being strongly suggestive of a regulatory function $[24,25]$.

\section{Discussion}

The development of robust protocols for the differentiation of DC from hESC lines, derived under cGMP conditions, offers a potentially unlimited source of cells with little variability between batches, which may be subjected to rigorous quality control. The potent immunostimulatory capacity of DC differentiated in this way has suggested that they will find a likely application in the presentation of tumour associated antigens to the T-cell repertoire, thereby overcoming many of the limitations inherent in the use of moDC for cancer immunotherapy [19]. Nevertheless, given the accumulation of evidence in favour of an additional role played by DC in the establishment and ongoing maintenance of immunological tolerance [3], the availability of DC differentiated from hESC suggests they may enjoy a broader remit. We have, for instance, proposed that hESC-derived DC might be exploited 

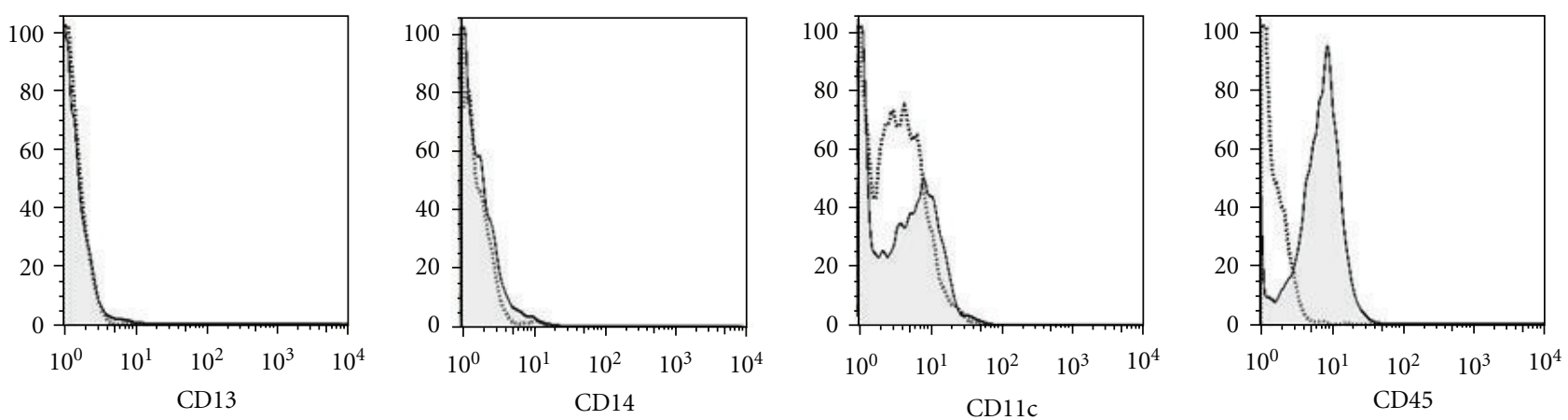

(a)

Gated on CD45 $5^{\text {int }}$
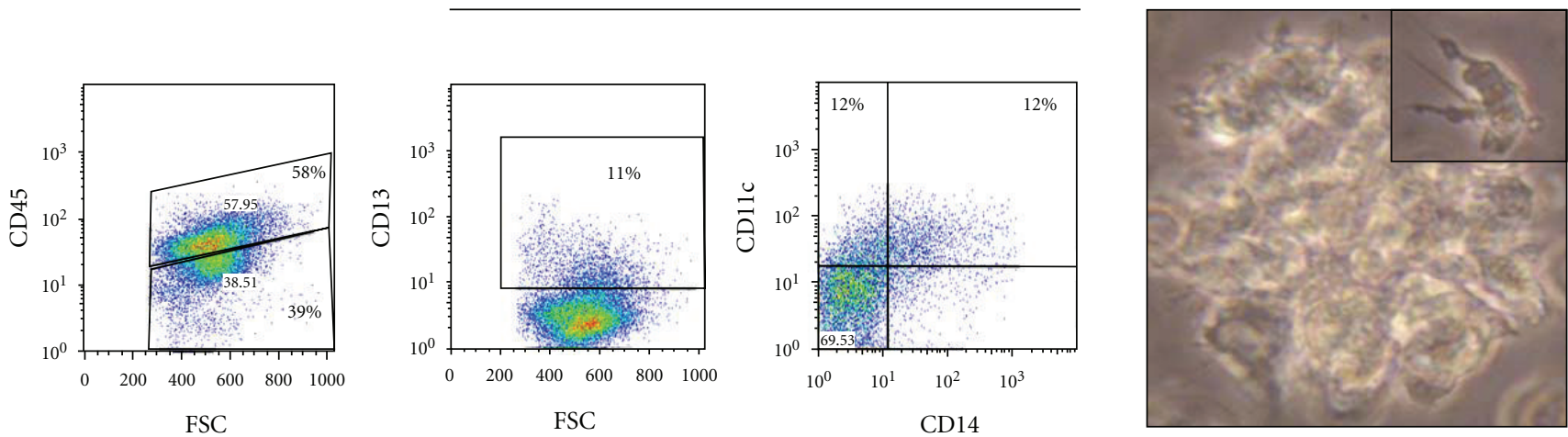

(b)

(c)

Gated on CD45 ${ }^{\text {hi }}$
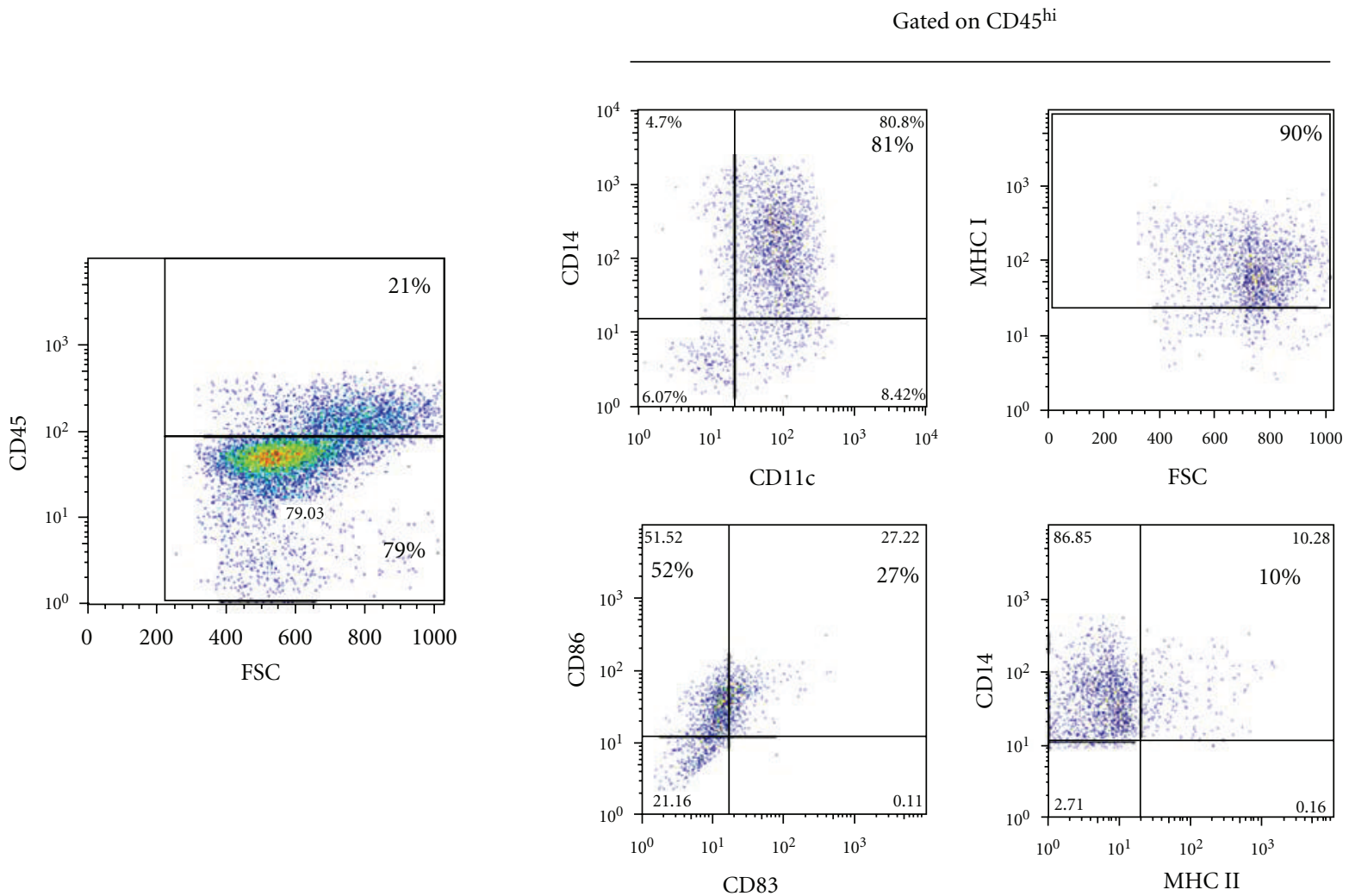

(d)

FIgUre 2: Continued. 

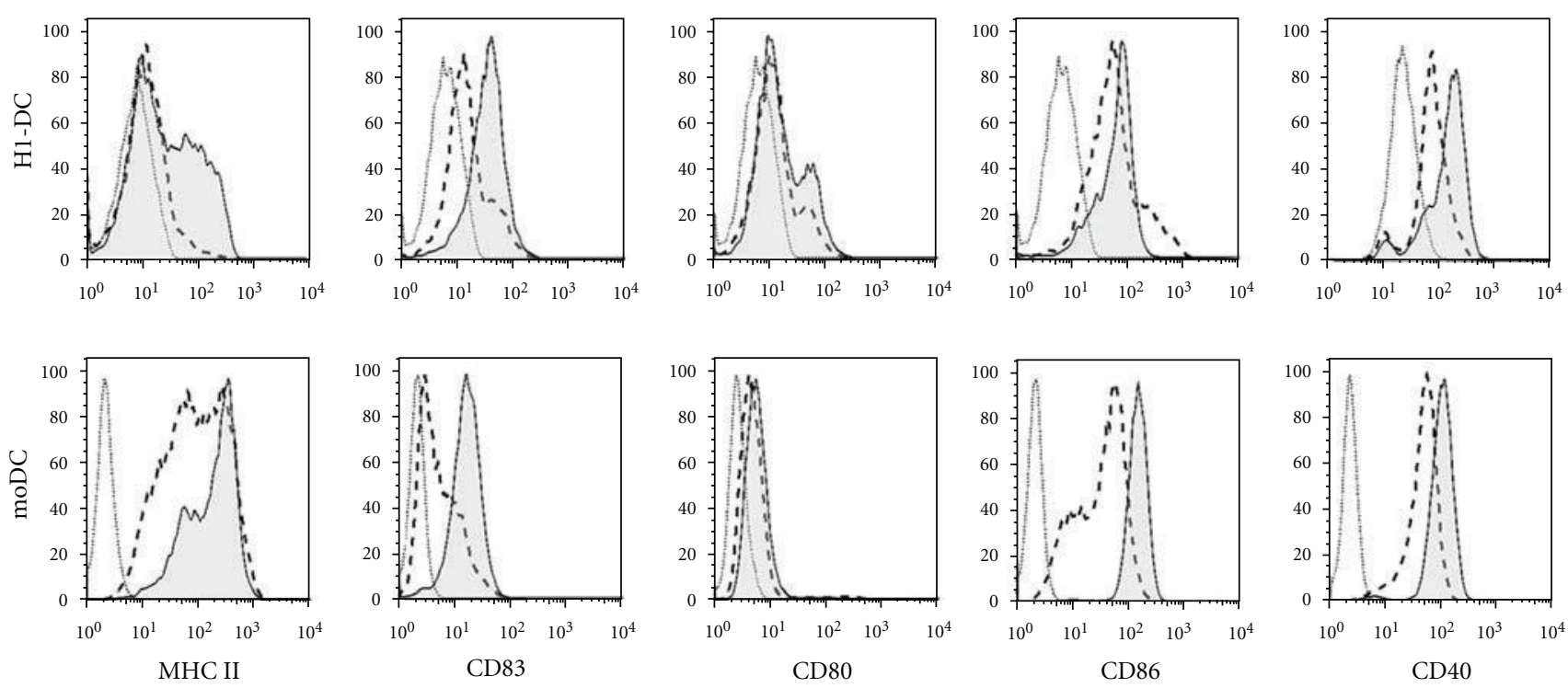

(e)

Figure 2: Time course of DC differentiation from H1 hESC. Cells were harvested from cultures at various time points and analysed by flow cytometry for the onset of hematopoiesis and the appearance of DC. (a) Cells harvested at day 20 of culture showing expressing of CD45 but lack of myeloid commitment, as evidenced by staining for CD13, CD14, and CD11c. Open histograms show levels of background staining using isotype-matched control antibodies. (b) Appearance of CD45 ${ }^{\text {int }}$ cells at day 27 of culture, accompanied by the upregulation of myeloid-specific markers. (c) Photomicrograph, taken at day 28 of culture, showing the morphology of DC, including veils of cytoplasm and long dendrites (inset) ( $\times 40$ magnification). (d) Cells harvested at day 33 of culture, showing the appearance of a CD45i population containing predominantly DC progenitors expressing CD14, CD11c, CD86 and MHC class I. (e) Phenotype of immature and mature H1DCs compared with human moDC. DCs were cultured either in medium alone or medium supplemented with the maturation cocktail and stained for MHC class II, the maturation marker CD83 and classical costimulatory molecules. Dead cells were excluded from the analysis using 7-AAD. Dashed histograms show the phenotype of immature DCs while the filled histograms represent mature DCs. Open histograms depict background staining using isotype-matched controls.

to induce tolerance to the alloantigens they express, thereby conditioning recipients to accept replacement tissues differentiated from the same parent cell line [7]. This prospect is, however, contingent on the development of clinically compliant strategies to ensure the stable tolerogenicity of DC generated in this way. While the introduction of transgenes, such as PD-L1, at the ESC stage might confer on the resulting DC an immunomodulatory function [8], the additional regulatory hurdles encountered by the administration to patients of genetically modified cells, has fuelled attempts to identify approved pharmacological agents that coerce DC to adopt a protolerogenic phenotype [10].

Rapamycin is one such agent routinely exploited for its immunosuppressive properties in the treatment of allograft rejection but which has been shown to exert a profound effect on the function of individual components of the immune system, including DC. Indeed, treatment of DC with rapamycin in vitro has been demonstrated to arrest them in an immature or semimature state rendering them tolerogenic [11-13]. Accordingly, in various preclinical transplantation models, administration of rapamycin-treated recipient DC, pulsed with a source of donor alloantigens, secured the longterm survival of organ allografts [14-16]. If such a conditioning regime could be applied to DC differentiated from hESC, it may prove feasible to establish operational tolerance to the alloantigens they endogenously express, in advance of CRT. As a first step towards this goal, we have demonstrated the sensitivity of H1-DC to rapamycin which significantly reduces their immunostimulatory properties in the allogeneic MLR (Figure 3(b)), an in vitro correlate of the direct pathway of alloantigen presentation. Furthermore, rapamycin substantially augments their ability to polarise responding $\mathrm{CD} 4^{+} \mathrm{T}$ cells towards a regulatory phenotype (Figure 4(b)), as determined by their sustained expression of Foxp3 and adoption of a CTLA $4^{+} \mathrm{CD} 127^{-}$phenotype. Furthermore, our preliminary results indicate that, while maturation of H1-DC induces secretion of high levels of the inflammatory cytokine IL-6 [19], prior exposure to rapamycin significantly reduces IL-6 production, possibly guiding responding $\mathrm{T}$ cells away from Th1/Th17 commitment towards a Treg phenotype. These results strongly suggest, therefore, that rapamycin may have the desirable properties of preventing activation of alloreactive $T$ cells through both the direct and indirect pathways of alloantigen presentation, the induction of Treg cells potentially modulating responsiveness to indirectly presented alloantigens that have been reprocessed by endogenous recipient DC. In contrast to our findings with H1-DC, rapamycin-treatment of moDC had only a modest impact on their immunostimulatory capacity and little effect on their surface phenotype. Although our results are contrary to 


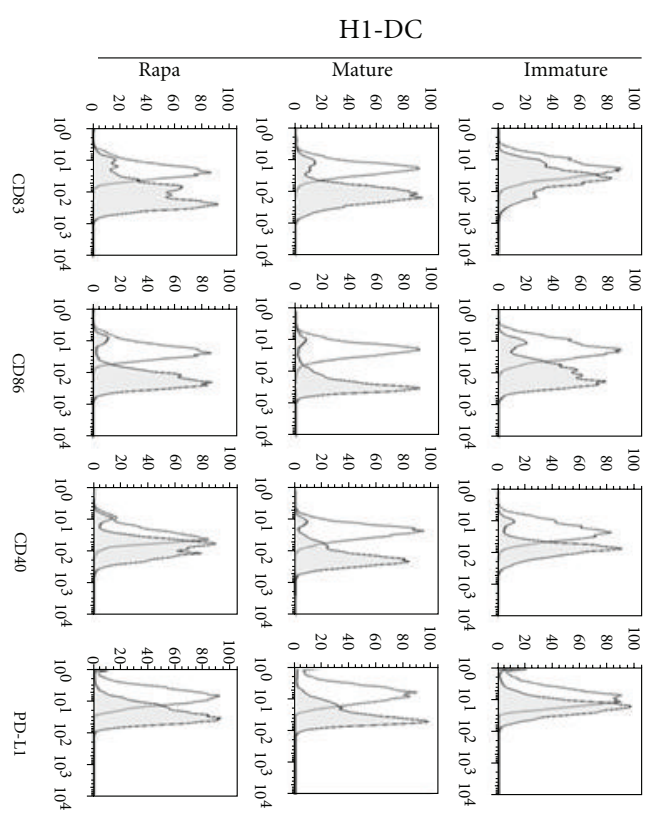

(a)

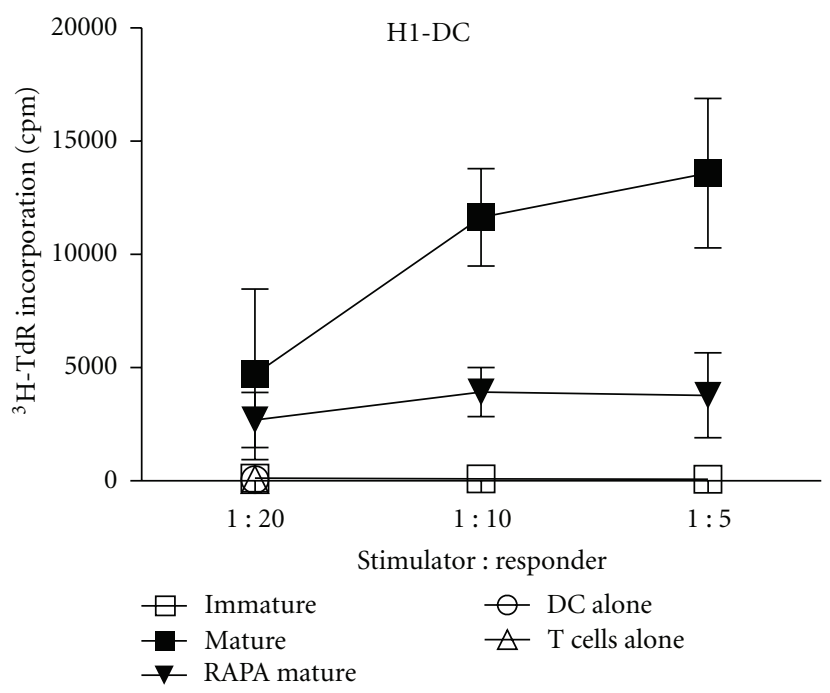

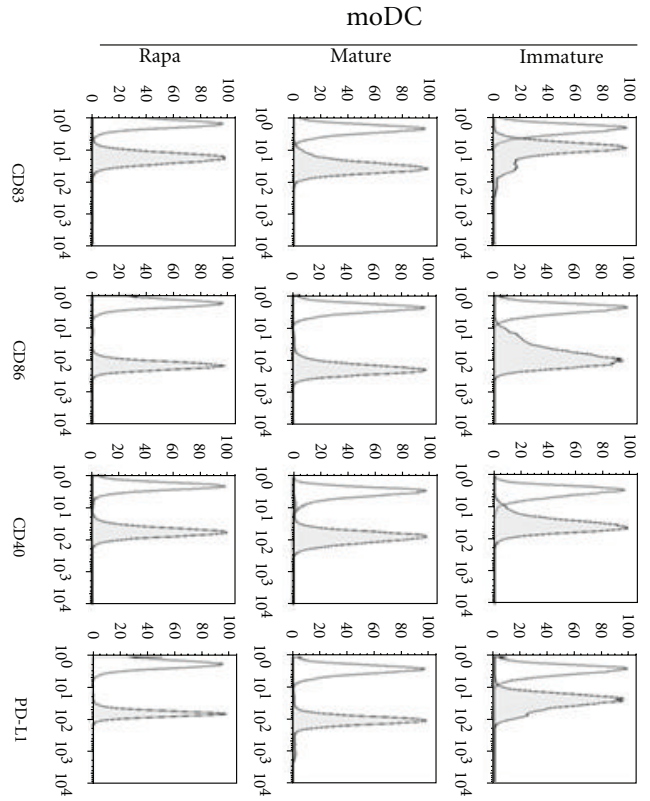

(b)

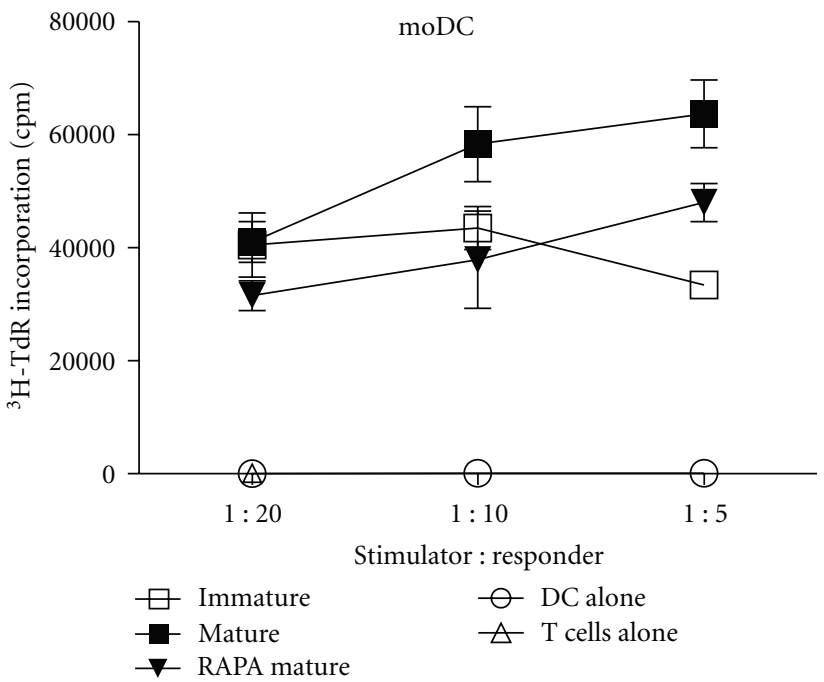

(c)

Figure 3: Effect of rapamycin (Rapa) on the phenotype and function of H1-DC. DCs were either untreated, matured in response to the maturation cocktail or treated with Rapa for 3 days prior to maturation. (a) H1-DC stained for the expression of the maturation marker CD83, the costimulatory molecules CD86 and CD40, as well as the inhibitory receptor PD-L1. Dead cells were excluded from analysis using 7-AAD. Open histograms represent the level of background staining using appropriate isotype-matched controls. Data from one of 3 independent experiments are shown. (b) Phenotypic analysis of control populations of moDC treated and stained in parallel with rapamycin. (c) Effect of rapamycin on the allostimulatory capacity of DC in the allogeneic MLR. DCs were mitotically-inactivated using mitomycin $\mathrm{C}$ and plated in triplicate at a top dose of $10^{4}$ cells per well of a 96-well round-bottomed plate; naïve CD4 ${ }^{+} \mathrm{T}$ cells were plated at $5 \times 10^{4}$ cells/well. Cells were incubated for 5 days before pulsing with ${ }^{3} \mathrm{H}$-thymidine overnight. Graphs show the mean of triplicate cultures \pm S.D. Data are shown from one experiment, representative of 3 independent experiments.

some other reports $[12,18]$, many studies have typically used higher concentrations of rapamycin and regimes for the maturation of moDC involving exposure to bacterial products, such as lipopolysaccharide, which target different intracellular signalling pathways from those solicited upon culture with the cocktail of proinflammatory cytokines used in these studies.
Despite the profound effect that rapamycin exerts on the functional potential of H1-DC, phenotypic analysis of cells treated with the compound was largely unremarkable, with the exception that upregulation of the costimulatory molecule $\mathrm{CD} 40$ upon maturation was prevented by prior exposure to the compound. The significance of these findings may lie in the growing appreciation of the role played by CD40 as 

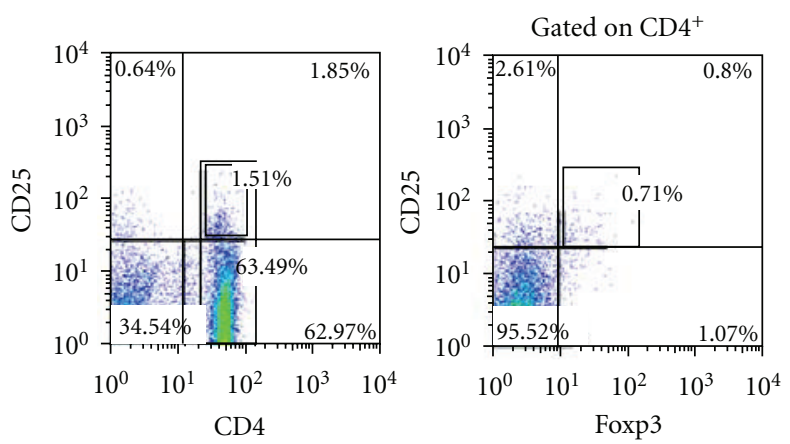

(a)

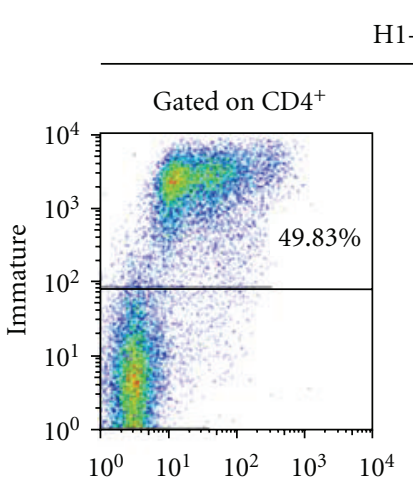

H1-DC
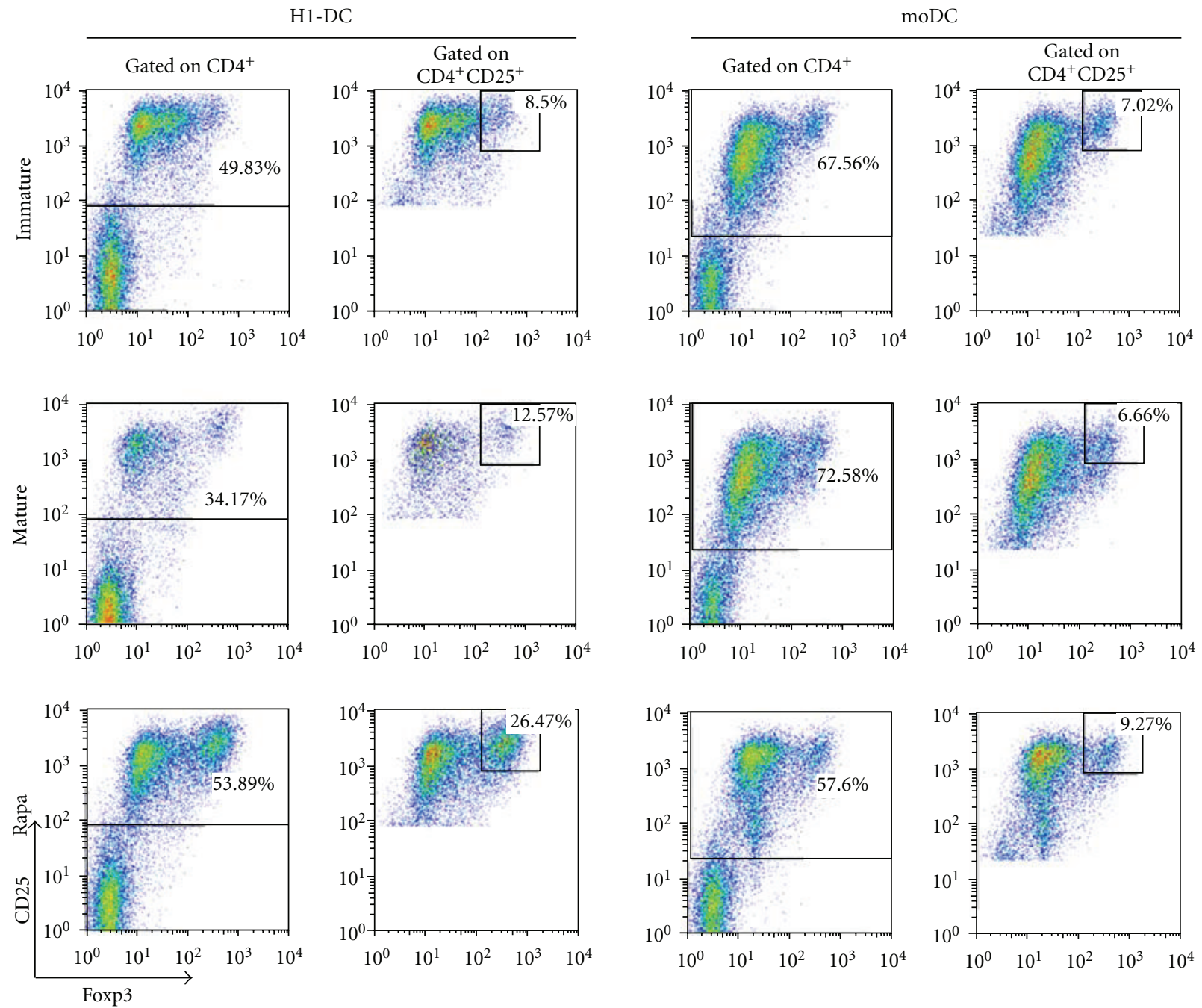

(b)

Figure 4: Enhanced capacity of rapamycin-treated H1-DC to promote Treg induction. (a) The starting population of naive CD4 ${ }^{+}$T cells was analysed by flow cytometry for the expression of CD25 and Foxp3, markers associated with commitment of T cells to the regulatory T cell lineage. (b) Rapamycin enhances the capacity of H1-DC to induce Treg cells compared to moDC. DCs were either untreated, matured with the maturation cocktail or treated with rapamycin for 3 days prior to maturation. DCs were harvested, washed, and plated at $2 \times 10^{5}$ per well with $10^{6}$ naive $\mathrm{CD}^{+} \mathrm{T}$ cells per well of a 24 -well plate to yield a ratio of DC: T cells of $1: 5$. On day 7, cocultures were stained for CD4, CD25, and Foxp3 and analysed. Dead cells were excluded from the analysis using 7-AAD staining. Data from one experiment representative of 4 independent experiments are shown. 

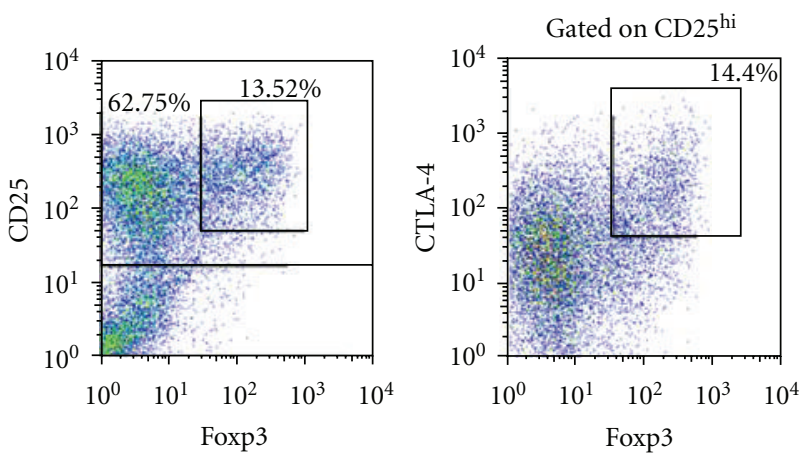

(a)
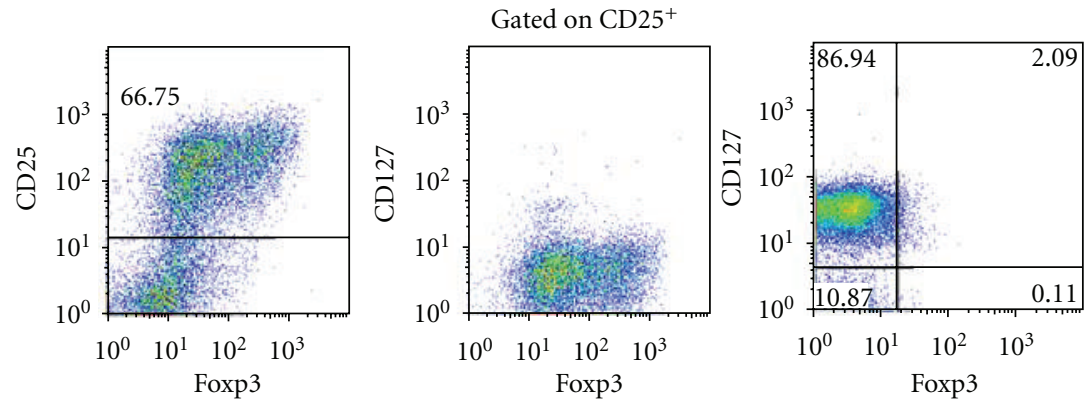

(b)

Figure 5: Phenotypic characterisation of putative CD25 hi Foxp $3^{+}$Treg cells from cocultures of DC and naïve T cells. The CD25 ${ }^{\text {hi }}$ Foxp $3^{+}$ population expresses CTLA-4 (a) but lacks expression of CD127 in comparison with control Foxp3- $\mathrm{T}$ cells (b), consistent with the reported phenotype of bona fide Treg cells.

the fulcrum on which the balance between tolerance and immunity has been shown to pivot. For instance, the administration to mice of CD40-/- DC laden with foreign antigen was shown to induce profound antigen-specific tolerance upon subsequent immunization, results which are consistent with the induction of a repertoire of Treg cells [26]. Furthermore, in mice receiving foreign antigen chemically conjugated to CD205-specific mAb as a way of delivering antigen to DC in the steady state, the induction of tolerance could be abrogated in favour of systemic immunity by the concomitant administration of agonistic antibodies specific for CD40 $[4]$.

It is the central role played by CD40 in a transplantation setting that underlies the success of strategies for intervening in allograft rejection based on the blockade of CD40CD154 interactions [27]. Although unanticipated complications associated with the use of $\mathrm{mAb}$ specific for CD154 have hindered the application of such a strategy to the clinic; the long-term acceptance of allografts in mice was found to bear the distinctive features of regulation, including linked suppression and infectious tolerance $[28,29]$. A conditioning regime that limits the delivery of CD40 signalling by donor DC might, therefore, be anticipated to predispose recipients towards tolerance based on the generation of a repertoire of alloantigen-specific Treg cells. Indeed, the level of expression of CD40 has been shown to be critical in determining the outcome of antigen recognition in a model of Leishmania donovani infection, high levels of expression inducing effector $\mathrm{T}$ cells, low levels favouring polarisation towards a Treg phenotype [30]. Furthermore, blockade of the
CD40-CD154 axis in combination with rapamycin was shown to achieve tolerance even across a xenogeneic barrier [31]. Although the mechanisms involved were not specifically elucidated in this study, it may be significant in our own experiments that PD-L1 expression by H1-DC was unaffected by rapamycin treatment, being upregulated in response to maturation stimuli, irrespective of prior exposure to the compound. Given the essential role described for PD-L1 in polarisation of naïve $\mathrm{T}$ cells towards a Treg cell phenotype [23], it is tempting to speculate that it is by altering the critical balance between costimulatory and inhibitory signals delivered by H1-DC, that rapamycin treatment strongly favours a tolerogenic profile.

\section{Conclusions}

We have demonstrated previously that hESC may be differentiated into populations of immunogenic DC whose properties may be exploited in regimes of cancer immunotherapy. Here, we extend this paradigm by showing that our protocols are fully compliant with the use of rapamycin which favours a protolerogenic phenotype of the resulting DC. Our results pave the way for the future use of rapamycin-conditioned hESC-derived DC in regimes for the induction of tolerance, as a prelude to CRT.

\section{Conflict of Interests}

A. Reddy and K. P. Nishimoto declare a potential financial conflict of interests as employees of Geron Corporation. 


\section{Acknowledgments}

The authors are grateful to Tim Davies, Naoki Ichiryu, and Simon Hackett for helpful discussions and to Lara Whitmore for administrative assistance. A. J. Leishman is the recipient of an MRC capacity building studentship, awarded to the Oxford Stem Cell Institute. This work was performed under a sponsored research agreement between the University of Oxford and Geron Corporation, with additional support from the Medical Research Council UK, in the form of Grant G0802538 awarded to P. J. Fairchild.

\section{References}

[1] I. Klimanskaya, N. Rosenthal, and R. Lanza, "Derive and conquer: sourcing and differentiating stem cells for therapeutic applications," Nature Reviews Drug Discovery, vol. 7, no. 2, pp. 131-142, 2008.

[2] P. J. Fairchild, N. J. Robertson, S. L. Minger, and H. Waldmann, "Embryonic stem cells: protecting pluripotency from alloreactivity," Current Opinion in Immunology, vol. 19, no. 5, pp. 596602, 2007.

[3] R. M. Steinman and J. Banchereau, "Taking dendritic cells into medicine," Nature, vol. 449, no. 7161, pp. 419-426, 2007.

[4] D. Hawiger, K. Inaba, Y. Dorsett et al., "Dendritic cells induce peripheral $\mathrm{T}$ cell unresponsiveness under steady state conditions in vivo," Journal of Experimental Medicine, vol. 194, no. 6, pp. 769-779, 2001.

[5] S. F. Yates, A. M. Paterson, K. F. Nolan et al., "Induction of regulatory T cells and dominant tolerance by dendritic cells incapable of full activation," Journal of Immunology, vol. 179, no. 2, pp. 967-976, 2007.

[6] M. V. Dhodapkar, R. M. Steinman, J. Krasovsky, C. Munz, and N. Bhardwaj, "Antigen-specific inhibition of effector T cell function in humans after injection of immature dendritic cells," Journal of Experimental Medicine, vol. 193, no. 2, pp. 233-238, 2001.

[7] P. J. Fairchild, S. Cartland, K. F. Nolan, and H. Waldmann, "Embryonic stem cells and the challenge of transplantation tolerance," Trends in Immunology, vol. 25, no. 9, pp. 465-470, 2004.

[8] S. Senju, H. Suemori, H. Zembutsu et al., "Genetically manipulated human embryonic stem cell-derived dendritic cells with immune regulatory function," Stem Cells, vol. 25, no. 11, pp. 2720-2729, 2007.

[9] S. Hirata, S. Senju, H. Matsuyoshi, D. Fukuma, Y. Uemura, and Y. Nishimura, "Prevention of experimental autoimmune encephalomyelitis by transfer of embryonic stem cell-derived dendritic cells expressing myelin oligodendrocyte glycoprotein peptide along with TRAIL or programmed death-1 ligand 1," Journal of Immunology, vol. 174, no. 4, pp. 1888-1897, 2005.

[10] A. J. Leishman, K. M. Silk, and P. J. Fairchild, "Pharmacological manipulation of dendritic cells in the pursuit of transplantation tolerance," Current Opinion in Organ Transplantation, vol. 16, no. 4, pp. 372-378, 2011.

[11] H. R. Turnquist, G. Raimondi, A. F. Zahorchak, R. T. Fischer, Z. Wang, and A. W. Thomson, "Rapamycin-conditioned dendritic cells are poor stimulators of allogeneic $\mathrm{CD} 4^{+} \mathrm{T}$ cells, but enrich for antigen-specific Foxp $3^{+} \mathrm{T}$ regulatory cells and promote organ transplant tolerance," Journal of Immunology, vol. 178, no. 11, pp. 7018-7031, 2007.

[12] V. Sordi, G. Bianchi, C. Buracchi et al., "Differential effects of immunosuppressive drugs on chemokine receptor CCR7 in human monocyte-derived dendritic cells: selective upregulation by rapamycin," Transplantation, vol. 82 , no. 6, pp. 826834, 2006.

[13] W. Reichardt, C. Dürr, D. Von Elverfeldt et al., "Impact of mammalian target of rapamycin inhibition on lymphoid homing and tolerogenic function of nanoparticle-labeled dendritic cells following allogeneic hematopoietic cell transplantation," Journal of Immunology, vol. 181, no. 7, pp. 4770-4779, 2008.

[14] J. M. Sacks, Y. R. Kuo, A. Taieb et al., "Prolongation of composite tissue allograft survival by immature recipient dendritic cells pulsed with donor antigen and transient low-dose immunosuppression," Plastic and Reconstructive Surgery, vol. 121, no. 1, pp. 37-49, 2008.

[15] R. Ikeguchi, J. M. Sacks, J. V. Unadkat et al., "Long-term survival of limb allografts induced by pharmacologically conditioned, donor alloantigen-pulsed dendritic cells without maintenance immunosuppression," Transplantation, vol. 85, no. 2, pp. 237-246, 2008.

[16] T. Taner, H. Hackstein, Z. Wang, A. E. Morelli, and A. W. Thomson, "Rapamycin-treated, alloantigen-pulsed host dendritic cells induce Ag-specific T cell regulation and prolong graft survival," American Journal of Transplantation, vol. 5, no. 2, pp. 228-236, 2005.

[17] E. K. Horibe, J. Sacks, J. Unadkat et al., "Rapamycin-conditioned, alloantigen-pulsed dendritic cells promote indefinite survival of vascularized skin allografts in association with $\mathrm{T}$ regulatory cell expansion," Transplant Immunology, vol. 18, no. 4, pp. 307-318, 2008.

[18] M. Haidinger, M. Poglitsch, R. Geyeregger et al., "A versatile role of mammalian target of rapamycin in human dendritic cell function and differentiation," Journal of Immunology, vol. 185, no. 7, pp. 3919-3931, 2010.

[19] S. Y. Tseng, K. P. Nishimoto, K. M. Silk et al., "Generation of immunogenic dendritic cells from human embryonic stem cells without serum and feeder cells," Regenerative Medicine, vol. 4, no. 4, pp. 513-526, 2009.

[20] C. Xu, M. S. Inokuma, J. Denham et al., "Feeder-free growth of undifferentiated human embryonic stem cells," Nature Biotechnology, vol. 19, no. 10, pp. 971-974, 2001.

[21] Y. Li, S. Powell, E. Brunette, J. Lebkowski, and R. Mandalam, "Expansion of human embryonic stem cells in defined serumfree medium devoid of animal-derived products," Biotechnology and Bioengineering, vol. 91, no. 6, pp. 688-698, 2005.

[22] A. M. Woltman, J. W. De Fijter, S. W. A. Kamerling et al., "Rapamycin induces apoptosis in monocyte- and CD34-derived dendritic cells but not in monocytes and macrophages," Blood, vol. 98, no. 1, pp. 174-180, 2001.

[23] L. Wang, K. Pino-Lagos, V. C. De Vries, I. Guleria, M. H. Sayegh, and R. J. Noelle, "Programmed death 1 ligand signaling regulates the generation of adaptive Foxp $3^{+} \mathrm{CD} 4^{+}$regulatory T cells," Proceedings of the National Academy of Sciences of the United States of America, vol. 105, no. 27, pp. 9331-9336, 2008.

[24] N. Seddiki, B. Santner-Nanan, J. Martinson et al., "Expression of interleukin (IL)-2 and IL-7 receptors discriminates between human regulatory and activated T cells," Journal of Experimental Medicine, vol. 203, no. 7, pp. 1693-1700, 2006.

[25] W. Liu, A. L. Putnam, Z. Xu-yu et al., "CD127 expression inversely correlates with FoxP3 and suppressive function of human $\mathrm{CD}^{+} \mathrm{T}$ reg cells," Journal of Experimental Medicine, vol. 203, no. 7, pp. 1701-1711, 2006.

[26] K. Hochweller and S. M. Anderton, "Systemic administration of antigen-loaded CD40-deficient dendritic cells mimics 
soluble antigen administration," European Journal of Immunology, vol. 34, no. 4, pp. 990-998, 2004.

[27] C. P. Larsen, E. T. Elwood, D. Z. Alexander et al., "Long-term acceptance of skin and cardiac allografts after blocking CD40 and CD28 pathways," Nature, vol. 381, no. 6581, pp. 434-438, 1996.

[28] K. Honey, S. P. Cobbold, and H. Waldmann, "CD40 ligand blockade induces CD4+ T cell tolerance and linked suppression," Journal of Immunology, vol. 163, no. 9, pp. 4805-4810, 1999.

[29] L. Graca, K. Honey, E. Adams, S. P. Cobbold, and H. Waldmann, "Cutting edge: anti-CD154 therapeutic antibodies induce infectious transplantation tolerance," Journal of Immunology, vol. 165, no. 9, pp. 4783-4786, 2000.

[30] S. Martin, R. Agarwal, G. Murugaiyan, and B. Saha, "CD40 expression levels modulate regulatory $\mathrm{T}$ cells in Leishmania donovani infection," Journal of Immunology, vol. 185, no. 1, pp. 551-559, 2010.

[31] Y. D. Muller, G. Mai, P. Morel et al., "Anti-CD154 mAB and rapamycin induce $\mathrm{T}$ regulatory cell mediated tolerance in ratto-mouse islet transplantation," PLoS One, vol. 5, no. 4, Article ID e10352, 2010. 

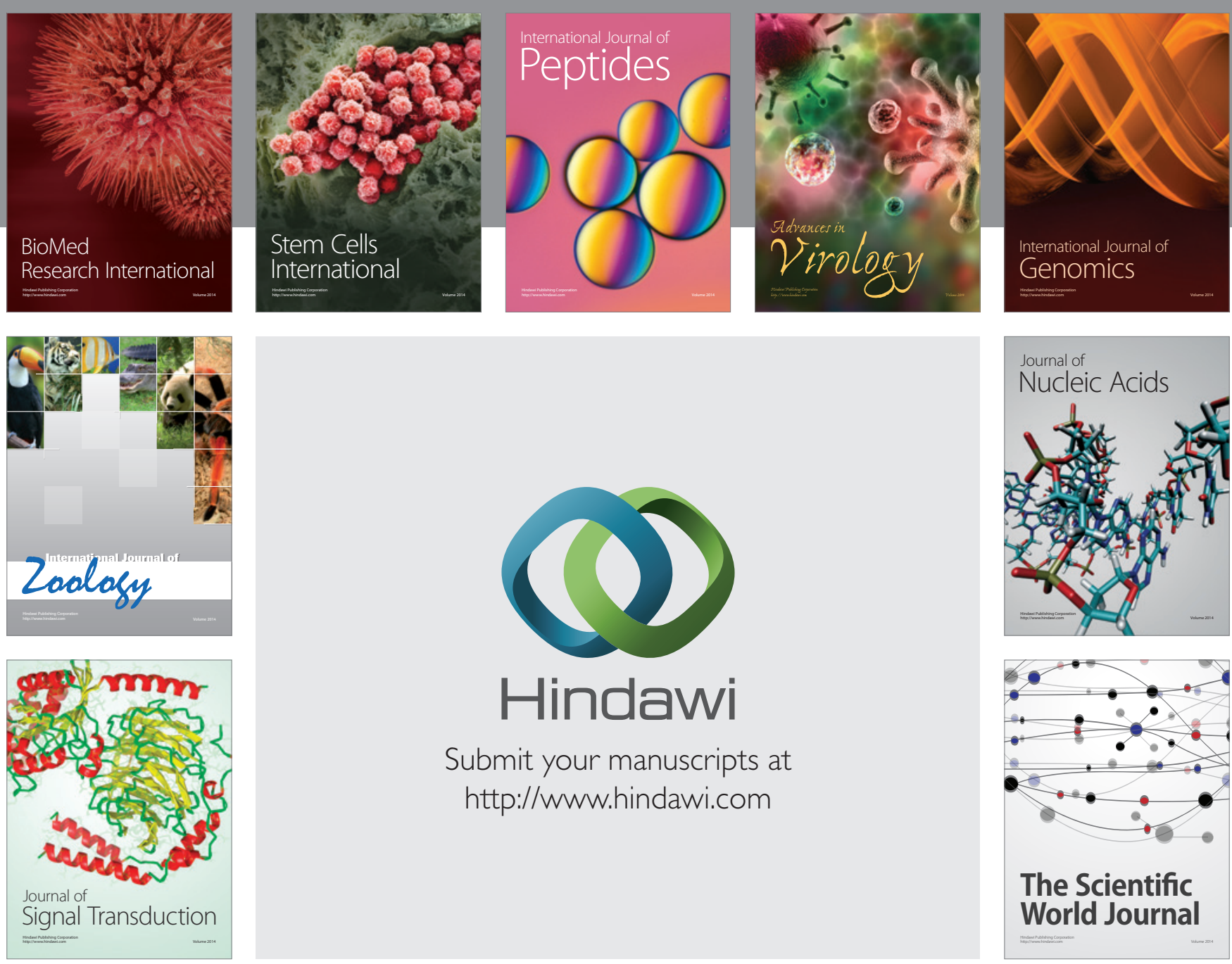

Submit your manuscripts at

http://www.hindawi.com
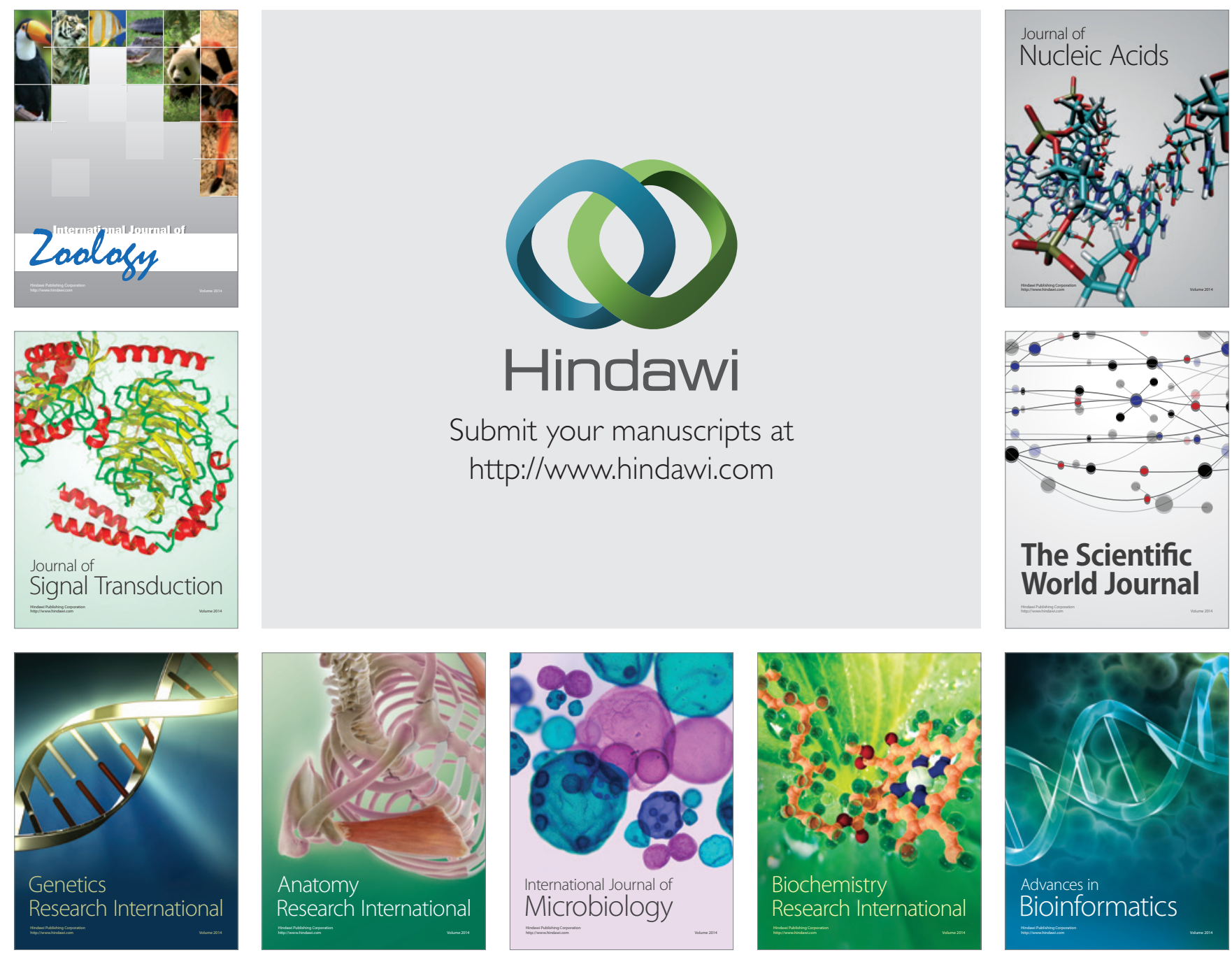

The Scientific World Journal
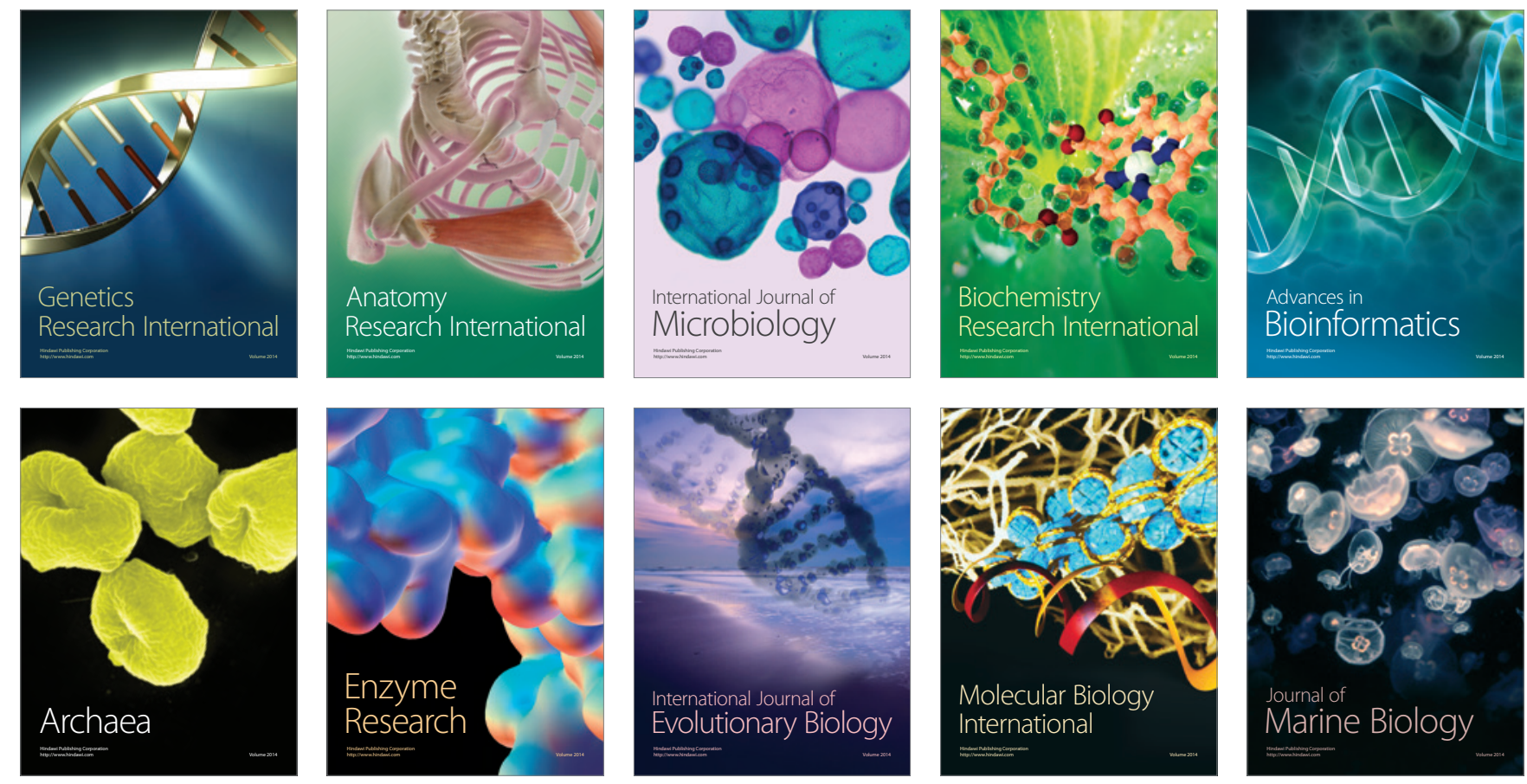